\title{
Case Study: Supporting Students with an Autistics Spectrum Disorder
}

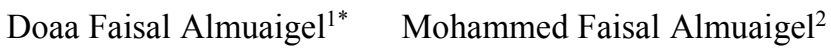 \\ 1.College of Education, Imam Mohammed Bin Saud University, Riyadh, Kingdom of Saudi Arabia \\ 2.College of Medicine, King Faisal University, Alahsa, Kingdom of Saudi Arabia
}

\begin{abstract}
Autism spectrum disorders (ASDs) are a group of developmental disabilities characterized by impairments in social interaction and communication and by restricted, repetitive, and stereotyped patterns of behavior. there is increasing concern about how to teach and support students with autism in the school environment and how to meet the best of their needs. Teachers are required to demonstrate programming and planning that accommodates all learners. The aim of this case report is to demonstrate how to cater to the teaching and learning needs of a young student with autism in a mainstream school.The Method of this case study is a 6 years old boy were three strategies used for 1 year; (1) Treatment and Education of Autistic and Related Communication Handicapped Children (TEACCH) program, (2) Antecedent Strategies in the Classroom (ASC), and (3) visual cues program (VCP). The Results as the following; (A)TEACCH: Increasing Ahmad's participation in class activities has the added benefit of increasing his social acceptance amongst his peers and improving his overall social skills. (B) ASC: Ahmad begin to spend more time sitting on the mat and participating in activities, rather than actively walking around the classroom and being disruptive. (C) VCP: Assist Ahmad to develop his play skills and improves his friendships thereby facilitating social inclusion in the school environment. (D) (Collaboration and Partnerships: The role of the teacher needs to be as an equal as partner with Ahmad's parents, not professional as expert, in order to facilitate a successful partnership. As a Conclusion; Effective collaboration amongst key stakeholders is important in addressing the difficulties experienced by students with ASD in order to support and improve their participation and engagement within the school environment and also within the wider community.

Keywords: Autism spectrum disorder, supporting students, programs, strategies, Treatment and Education of Autistic and Related Communication Handicapped Children, Antecedent Strategies in the Classroom, visual cues program.
\end{abstract}

DOI: $10.7176 / \mathrm{JEP} / 10-5-06$

\begin{abstract}
Abbreviation
Autism spectrum disorder (ASD), Treatment and Education of Autistic and Related Communication Handicapped Children (TEACCH), Antecedent Strategies in the Classroom (ASC), visual cues program (VCP), Diagnostic Statistician Manual 5 (DSM 5), Individual Education Plan (IEP
\end{abstract}

\section{Introduction}

Autism spectrum disorders (ASDs) are a group of developmental disabilities characterized by impairments in social interaction and communication and by restricted, repetitive, and stereotyped patterns of behavior (Lord, C 2012). The Diagnostic Statistician Manual 5 (DSM 5) also provides a severity rating scale that ranges from requiring support to requiring very substantial support. This severity rating scale may assist education professionals, or teachers, to determine what level of planning and support is needed for their students with autism based on where they rate on this scale. The following case study is used to demonstrate how to cater the teaching and learning needs of a young student with autism in a mainstream school.

ASD affects a significant proportion of students in the classroom. Recent figures suggest that approximately 1 in 68 children are diagnosed with autism (Federal Information and News Dispatch, 2014). These figures vary across the world, however there is increasing concern about how to teach and support students with autism in the school environment and how to meet the best of their needs. Teachers are required to demonstrate programming and planning that accommodates all learners, but more specifically students with autism, as they make up a larger proportion of the student population. Additionally, teachers must ensure that the overall health and well being of students with autism are provided for and this inevitably involves collaborating with other teachers and also the families of these students. There are essay discusses cases of key teaching and programming within a supportive school environment for a student with ASD by using a case study; a six year old male with autism, Ahmad, who has communication difficulties. The framework for structured teaching by Mesibov, Shea, and McCaskill (2012) in conjunction with teaching strategies by Marks et al., (2003) and Hart and Whalon (2008) is used to design an education intervention for Ahmad's communication difficulties in the school environment while discussing the implications for teachers, the school community, and his family. The following case study used to demonstrate how to cater to the teaching and learning needs of a young student with autism in a 
mainstream school.

\section{Case study}

Ahmad is a 6 year old boy who has been recently diagnosed with ASD using the new guidelines of the DSM Ahmad is rated as requiring substantial support in relation to his communication. He was non-verbal up until the age of 3. Ahmad currently has minimal verbal skills and prefers not to maintain eye contact. He is more likely to repeat words that are spoken and needs prompting to initiate speech. Ahmad is interested in dinosaurs and enjoys playing on the computer, in particular, using his iPad to watch dinosaur movies and to play dinosaur games. He has limited friendships and struggles to interact with his peers. Ahmad is the eldest of two children; he also has a younger brother who is two years of age. Ahmad's father is regularly away with work trips, however Ahmad's mother does not work and is a homemaker who looks after the two children full-time. Ahmad's mother is highly supportive and actively involved in Ahmad's schooling.

Ahmad attends Grade 1 at a local mainstream primary school. This primary school adopts an inclusive education approach and prefers to include students in the classroom. The primary school employs two special education teachers who work full-time to support students with additional needs. Ahmad has been identified as a student in need of support at a local mainstream primary school. Ahmad experiences difficulty remaining seated in the classroom and prefers to actively move about during lessons. He also dislikes transitioning between different activities throughout the school day. Ahmad is withdrawn from the classroom each afternoon to complete quiet activities, as he is sensitive to noise and becomes aggressive and withdrawn from his peers and his teacher. Ahmad's parents would prefer that Ahmad is kept in the classroom at all times.

\section{Dimensions of Autism}

Teaching strategies that catering to the needs of students must start with knowledge of ASD and the different dimensions: social, communication, cognitive, sensory, and the repetitive and restrictive behaviors (Attwood, 2008). These dimensions are important because they affect the whole child and focusing on one dimension, such as communication, will inevitably be impacted by the other dimensions. The social and communication dimensions are sometimes difficult to separate due to their similarities, however the difference is that communication is used in the social dimension to make sense of and understand others behaviors and interaction. Each of these dimensions are experienced and expressed differently in each child with ASD, for no one child is alike (Mesibov, Shea, \& McCaskill, 2012). Consequently, the teaching and behavioral management strategies used for one child with ASD may not work for another child with ASD (Marks et al, 2003; Roberts, 2004); what is suggested for Ahmad may not work with another child with ASD who demonstrates similar communication difficulties. Therefore, teaching strategies are more effective if they are individualized to the needs of each child (Ganaie \& Bashir, 2014; Mesibov, Shea, \& McCaskill, 2012).

\section{Communication Dimension}

The characteristics of the communication dimension and its implications for the child with autism are outlined in Table 1.

Table 1 Communication characteristics and their implications

\begin{tabular}{|l|l|}
\hline Communication & Implication \\
\hline Non-verbal & Inability to follow instructions \\
Vocalising some sounds & Difficulty expressing feelings \\
Echolalia & Difficulty expressing needs and wants \\
Small sentences (3-4 or 4-5 words) & Behaving inappropriately in class or other settings \\
Verbally articulate & Reduced engagement in all environments \\
\hline
\end{tabular}

Children with ASD may experience a delay in receptive and expressive language (National Autism Center, 2011). The range of difficulties in communication characteristics range from being non-verbal, echolalia, vocalizing some sounds through to being able to use 4-5 word sentences or is verbally able to articulate quite well. Other characteristics include: echolalia, lacking skills to sustain communication, unusual voice quality, rhythm and pitch, and also disordered sentence structure (National Autism Center, 2011).

The implications of these characteristics are that the child with autism has difficulty following instructions and communicating their needs and wants; they may engage in undesirable behavior in the classroom or in other settings; and they may experience reduced engagement within the wider community (Bondy \& Frost, 2002) and within their families (Donnelly, 2008). The case study of Ahmad identifies that he experiences difficulty mainly with expressive language, however his teacher suspects that Ahmad may have difficulties with receptive language as well. Ahmad uses echolalia to communicate and needs prompting to initiate some sort of communication. These communication difficulties will be addressed in the next section with teaching strategies. 


\section{Teaching Strategies}

Ahmad's teacher has been trained in special education and therefore knowledgeable about different strategies to be used. Ahmad's teacher is aware of the importance of inclusive education for students with additional needs and is keen to promote Ahmad's active participation and engagement within the classroom and school environment. Inclusive education involves the active participation of all children of diverse abilities, including those children with disabilities in mainstream schools (Loreman, Deppeler, \& Harvey, 2005). Underpinning inclusive education is a philosophy of Education for All (United Nations, 2005) and the promotion and advocacy of the rights of people with disabilities (Carrington et al., 2012). As stated previously, the teaching strategies used on children with autism need to be individualised (Ganaie, 2014). Ahmad's teacher has decided to research some different teaching strategies in order to plan appropriate lessons for Ahmad. Table 2 details some key research on teaching students with ASD that Ahmad's teacher is reviewing to meet the communication needs of Ahmad. Each piece of research is analyzed and examined in relation to addressing Ahmad's communication difficulties.

Table 2 Key strategies for teaching students with ASD

\begin{tabular}{|c|c|c|}
\hline $\begin{array}{l}\text { Mesibov, Shea, \& } \\
\text { McCaskill (2012) }\end{array}$ & $\mathrm{tal}(2$ & ad Wha \\
\hline $\begin{array}{l}\text { TEACCH } \\
\text { program } \\
\text { Structured } \\
\text { teaching } \\
\text { Individualize all } \\
\text { strategies and } \\
\text { goals } \\
\text { Provide external } \\
\text { organisation of } \\
\text { space, time, and } \\
\text { the design of tasks } \\
\text { Use } \\
\text { supports visual } \\
\text { supplement or at } \\
\text { times substitute } \\
\text { for } \\
\text { language verbal } \\
\text { Use } \\
\text { interests to engage } \\
\text { attention and } \\
\text { learning }\end{array}$ & $\begin{array}{l}\text { Lesson Preparation } \\
\text { Highlight most important } \\
\text { concepts } \\
\text { Establish alternate modes } \\
\text { for completing assignments } \\
\text { Prepare the student } \\
\text { Maximise comprehension } \\
\text { and content retention } \\
\text { Graphic and visual } \\
\text { organisers } \\
\text { Mnemonic devices } \\
\text { Increase participation and } \\
\text { attention } \\
\text { Increase time on task } \\
\text { Prepare for instructional and } \\
\text { classroom transitions } \\
\text { Setting the stage }\end{array}$ & $\begin{array}{l}\text { Functional assessment of the academic environment } \\
\text { Self-management } \\
\text { Graphic organizers } \\
\text { Visual cues } \\
\text { Scripts } \\
\text { Flexible grouping strategies } \\
\text { Task analysis } \\
\text { Task selection and variation } \\
\text { Planned activity routines } \\
\text { Providing directions in multiple forms } \\
\text { Activity schedules } \\
\text { Video self-modeling } \\
\text { Initiating } \\
\text { Mnemonic devices } \\
\text { Priming } \\
\text { Visualization } \\
\text { Apply Universal Design Principles to student demonstration c } \\
\text { learning } \\
\text { Social stories } \\
\text { Collaboration with families and school professionals } \\
\text { Plan for generalisation }\end{array}$ \\
\hline
\end{tabular}

The first piece of research by Mesibov, Shea, \& McCaskill (2012) promotes the Treatment and Education of Autistic and Related Communication Handicapped Children (TEACCH) program using structured teaching. Mesibov, Shea, and Schopler (2005) present structured teaching strategies for students with ASD based on the specific culture and characteristics of autism. Structured teaching is an evidence-based practice (Smith-Myles, Smith, Aspy, Grossman, and Henry, 2012) that focuses on the physical organization of the environment, use of routines and schedules, and individualized teaching methods.

Ahmad's teacher has decided to implement some TEACCH strategies by planning Ahmad's environment and using visual schedules to promote his communication. The goal is to reduce the echolalia and also the level of undesirable behavior may be decreased thereby promoting and facilitating more productive communication. Ahmad experiences difficulty remaining seated in the classroom, therefore using a visual schedule would assist with increasing Ahmad's engagement (Mesibov \& Shea, 2008). Additionally, Ahmad was given a carpet square to sit on to promote his seating at an activity. This prompted by the visual schedule where Ahmad is guided to the appropriate behavior with a subsequent slow withdrawal of prompting. Increasing Ahmad's participation in class activities has the added benefit of increasing his social acceptance amongst his peers and improving his overall social skills.

The second piece of research by Marks et al (2003) promotes the use of antecedent strategies in the classroom, instead of other teaching strategies that focus on implementing consequences of undesirable behavior. The strategies promoted by Marks et al (2003) are a compilation of strategies that have worked with students with ASD in the classroom. These strategies focus on instructional management tips that require teachers to modify their curriculum and planning for students with ASD. Ahmad's teacher considers the following strategies to be useful in addressing Ahmad's communication needs: lesson preparation, establish alternate modes for 
completing assignments, prepare student, graphic and visual organizers, prepare for instructional and classroom transitions, and setting the stage. Ahmad also need his functional and summative assessment modified in order to demonstrate his developing understanding and knowledge of the curriculum. Ahmad's teacher was preparing Ahmad for these assessments by setting the stage and adjusting her pedagogical approach and the teaching environment by using simpler language, visual signs, modified assessments, and specifically addressing Ahmad's difficulty with transitions.

Ahmad needed more one-on-one support for specific activities to promote his communication and to prompt speech. For example, a literacy activity on creating a dinosaur story was assisted by having the teacher sit alongside Ahmad while he chooses pictures to cut out and place in the story, instead of text. Using Ahmad's interest in dinosaurs helps to motivate and increase his engagement in the activity (Mesibov, Shea, \& McCaskill, 2012). Ahmad prompted by the teacher to say the word of the picture before placing them in the story. By attending to Ahmad's communication needs, his overall participation and attention in class addressed and Ahmad begin to spend more time sitting on the mat and participating in activities, rather than actively walking around the classroom and being disruptive.

The third piece of research by Hart and Whalon (2008) identifies 20 teaching strategies for students with ASD. Hart and Whalon (2008) advocate that visual cues help students pay more attention, identify the task, and can be used within graphic organizers. Twachtman-Cullen (2008) supports the use of visual cues in addressing communication difficulties as it assists with overall comprehension and further recommends using social stories with pictures of facial expressions to help students with ASD imitate those expressions: this is especially useful for non-verbal or minimally verbal students such as Ahmad. The use of these visual cues and social stories assisted Ahmad to develop his play skills and to improve his friendships thereby facilitating social inclusion in the school environment (Wolfberg, McCracken, \& Tuchel, 2008). Planned activity routines in conjunction with visual and simple text activity schedules incorporated for Ahmad while planning at least one daily activity that involves dinosaurs (one of Ahmad's special interests). Again, using a special interest of Ahmad's helps his engagement in the activity (Mesibov \& Shea, 2008; Mesibov, Shea, \& McCaskill, 2012) and this used as a platform to facilitate Ahmad's communication.

\section{Researchers reflection}

the research have had experience teaching an six-year-old male student with autism in a mainstream school. One of this key goals was improving his communication skills.

The student was withdrawn from his peers to participate in one-on-one activities specifically designed to improve communication. A negative outcome of withdrawal is that the student may feel more stigmatized and socially isolated thereby potentially decreasing his social engagement and acceptance with peers in the school environment. Therefore Researchers would limit the amount of times this student is withdrawn from the classroom as well as look at options for increasing student engagement with peers by withdrawing a group of students with differing abilities so that the student of focus did not feel highlighted as being different and needing help.

The activities where the researchers used with this male student with ASD included traditional materials such as paper and pen and a timer to increase student focus on the task. The students was not engaged in this activity and much preferred learning through the use of an iPad with activities focusing on music, stories, and games. The use of iPads to promote communication to young children with autism has been found to be more successful than the use of strategies such as the picture exchange communication system (Lorah et al., 2013). A visual picture schedule was used to identify what was expected of the student and to allow the student to know what was about to happen. Marks et al (2003) and Hart and Whalon (2008) promote the use of visual cues and organisers for students with ASD. The use of a timer may be considered a visual cue and is also sensory. Previously, The researchers had put the timer on the table, however the timer agitated the student. The researchers needed to consider alternate forms of timing the activity by using different forms of timers, for example, a timer on the iPad that the student could help activate or a liquid up timer that did not make noise but was purely visual. The researchers had learnt that even if one strategy does not work, the overall basis of visual cues still works, The researchers just need to look at alternate sources of visual cues and to expand there imagination on the possibilities that could be used for the student. This same strategy of looking at alternate possibilities can be applied for all situations when teaching children with ASD.

\section{Conclusion}

Teachers play a pivotal role in the education of students with ASD. An awareness and understanding of ASD is essential to planning and delivering lessons that meet the needs of the student population. Students with ASD experience a range of difficulties in school environments and this may affect their overall participation and engagement in the classroom. These difficulties can be attributed to the nature of ASD and can have wide ranging impacts on their home and family life, their interaction and participation in the school environment, as 
well as their future in life. Effective collaboration amongst key stakeholders is important in addressing the difficulties experienced by students with ASD in order to support and improve their participation and engagement within the school environment and also within the wider community. The researchers recommend that these programs and strategies may work with a large number of ASD students, but it has to be applied with the students' interests, and many case studies should be applied by applying these programs and strategies.

\section{References}

Lord, C. (2012). Faculty of 1000 evaluation for Prevalence of autism spectrum disorders--Autism and Developmental Disabilities Monitoring Network, 14 sites, United States, 2008. F1000 - Post-publication Peer Review of the Biomedical Literature. doi:10.3410/f.717747905.793252855

Attwood, T. (2008). An overview of autism spectrum disorders. In K. Dunn-Baron \& P. Wolfberg (Eds.), Learners on the Autism Spectrum (pp. 18-43). Shawnee Mission, KA: Autism Asperger Publishing.

Bondy, A. \& Frost, L. (2002). A Picture's Worth: PECS and Other Visual Communication Strategies in Autism. New York, NY: Media Source.

Carrington, S., MacArthur, J. Kearney, A., Kimber, M., Mercer, L, Morton, M, \& Rutherford, G. (2012). Towards an inclusive education for all. In S. Carrington \& J. MacArthur (Eds.), Teaching in inclusive school communities (pp. 3-38). Milton, Queensland: John Wiley and Sons Australia.

Donnelly, J. A. (2008). Growing up with autism: One parent's perspective. In K. Dunn Buron \& P. Wolfberg (Eds.), Learners on the autism spectrum: Preparing highly qualified educators (pp. 307-318). Shawnee Mission, KA: Autism Asperger Publishing.

Federal Information and News Dispatch. (2014). Autism prevalence worsens: 1 in 68 Children suffer in U.S. Retrieved from http://search.proquest.com.libraryproxy.griffith.edu.au/docview/1510997533?accountid=14543

Ganaie, S. \& Bashir, A. (2014). Global autism: Autism, autism etiology, perceptions, epistemology, prevalence and action. International Journal of Clinical Terapeutics and Diagnosis, 2, 1-9.

Hart, J. E. \& Whalon, K. J. (2008). Promote academic engagement and communication of students with autism spectrum disorder in inclusive settings. Intervention in School and Clinic, 44, 116-120. doi $10.1177 / 1053451207310346$

Jacobsen, P. (2008). The education team: Positive, effective interdisciplinary collaboration. In K. Dunn Buron \& P. Wolfberg (Eds.), Learners on the autism spectrum: Preparing highly qualified educators (pp. 279-306). Shawnee Mission, KA: Autism Asperger Publishing.

Keen, D., \& Rodger, S. (2012). Working with parents of a newly diagnosed child with an Autism Spectrum Disorder: A guide for professionals. London, UK: Jessica Kingsley.

Lorah, E. R., Tincani, M., Dodge, J., Gilroy, S., Hickey, A. Hantula, D. (2013). Evaluating picture exchange and the iPad as a speech generating device to teach communication to young children with autism. Journal of Developmental and Physical Disabilities, 25, 637-649. doi 10.1007/s10882-013-9337-1

Loreman, T., Deppeler, J., \& Harvey, D. (2005). Inclusive education: A practical guide to supporting diversity in the classroom. New York: Routledge Falmer.

Marks, S. U., Shaw-Hegwer, J., Schrader, C., Longaker, T., Peters, I., Powers, F. \& Levine, M. (2003). Instructional management tips for teachers of students with autism spectrum disorder (ASD). Teaching Exceptional Children, 35, 50-54.

Mesibov, G. \& Shea, V. (2008). Structured teaching and environmental supports. In K. Dunn Buron \& P. Wolfberg (Eds.), Learners on the autism spectrum: Preparing highly qualified educators (pp. 115-138). Shawnee Mission, KA: Autism Asperger Publishing.

Mesibov, G., Shea, V., \& McCaskill, S. (2012). Structured teaching and the TEACCH program. In D. Zager, M. L. Wehmeyer, \& R. L. Simpson (Eds.), Educating students with autism spectrum disorders: Research-based principles and practices (pp.99-112). New York, NY: Routledge.

Mesibov, G. B., Shea, V., \& Schopler, E. (2005). The TEACCH approach to autism spectrum disorders. New York, NY: Springer.

National Autism Center. (2011). Evidence-based practice and autism in the schools: A guide to providing appropriate interventions to students with autism spectrum disorders. Retrieved from http://www.nationalautismcenter.org/learning/ed_manual.php

Roberts, J. (2003). A review of the research to identify the most effective models of best practice in the management of children with autism spectrum disorders. Sydney: Centre for Developmental Disability Studies.

Seligman, M., \& Darling, R. B. (2007). Professional-family interaction. In M. Seligman and R. B. Darling (Eds.), Ordinary families, special children (pp. 279-314). New York, NY: Guilford Press.

Simpson, R. L., Ganz, J. B., \& Mason, R. (2012). Social skills interventions and programming for learners with autism spectrum disorders. In D. Zager, M. L. Wehmeyer, \& R. L. Simpson (Eds.), Educating students with 
autism spectrum disorders: Research-based principles and practices (pp. 207-226). New York, NY: Taylor \& Francis.

Smith-Myles, B., Smith, S. M., Aspy, R., Grossman, B. G., \& Henry, S. (2012). Evidence-based practices. In D. Zager, M. L. Wehymeryer, \& R. L. Simpson (Eds.), Educating students with autism spectrum disorders (pp. 126-148). New York, NY: Taylor and Francis.

Twachtman-Cullen, D. (2008). Symbolic communication: Common pathways and points of departure. In K. Dunn-Baron \& P. Wolfberg (Eds.), Learners on the Autism Spectrum (pp. 89-114). Shawnee Mission, KA: Autism Asperger Publishing.

United Nations Educational, Scientific and Cultural Organisation. (2005). Guidelines for inclusion: Ensuring access to education for all. Paris: Author.

Wolfberg, P., McCrackern, H., \& Tuchel, T. (2008). Fostering peer play and friendships: Creating a culture of inclusion. In K. Dunn-Baron \& P. Wolfberg (Eds.), Learners on the Autism Spectrum (pp. 183-208). Shawnee Mission, KA: Autism Asperger Publishing. 